\section{Study of heart rate variability in dogs with brachycephalic syndrome that underwent rhinoplasty}

\author{
Estudo da variabilidade da frequência cardíaca em cães com \\ síndrome braquicefálica submetidos a rinoplastia
}

\begin{abstract}
Mário dos Santos Filho ${ }^{*}(\mathbb{D})$, Daniel Carvalho Hainfellner ${ }^{2}(\mathbb{D})$, Nathália Marques de Oliveira Lemos ${ }^{3}$ (D), Karen Denise Barbosa Macambira ${ }^{4}$ (D) Juliana Silva do Carmo ${ }^{4}$, Bruno Ricardo Soares Alberigi ${ }^{(D)}$, Carolina do Valle Aben Athar ${ }^{5}$ (D) , Aguinaldo Francisco Mendes Junior ${ }^{6}$ (D) , Cristiano Chaves Pessoa da Veiga ${ }^{7}$ (D). Ana Maria Barros Soares ${ }^{8}$ (D) Paulo de Tarso Landgraf Botteon ${ }^{9}$ (D) Julio Israel Fernandes ${ }^{9}$ (D) \& Jonimar Pereira Paiva ${ }^{9+}$ (D).

'Veterinary, MSc, Doctoral Student. Programa de Pós-Graduação em Medicina Veterinária, Ciências Clínicas, Instituto de Veterinária, Universidade Federal Rural do Rio de Janeiro - UFRRJ, Seropédica, RJ, Brasil.

Veterinary, MSc, Autonomus. Rio de Janeiro, RJ, Brasil.

Veterinary, Master 's Degree Student. Programa de Pós-Graduação em Medicina Veterinária, Ciências Clínicas, Instituto de Veterinária, Universidade Federal Rural do Rio de Janeiro - UFRRJ, Seropédica, RJ, Brasil.

${ }^{4}$ Veterinary, Veterinary Physician Resident. Cardiology and Respiratory Tract Diseases, Instituto de Veterinária, Universidade Federal Rural do Rio de Janeiro - UFRRJ, Seropédica, RJ, Brasil.

${ }^{5}$ Veterinary, MSc, Doctoral Student. Programa de Pós-Graduação em Medicina Veterinária, Ciências Clínicas, Instituto de Veterinária, Universidade Federal Rural do Rio de Janeiro - UFRRJ, Seropédica, RJ, Brasil

'Veterinary, MSc, doctoral student. Medicina Veterinária, Área de Concentração em Clínica e Reprodução Animal, Universidade Federal Fluminense (UFF), Niteroi, RJ, Brasil.

`Veterinary, Dsc, Administrative Technician. Hospital Veterinário de Pequenos Animais, Instituto de Veterinária, Universidade Federal Rural do Rio de Janeiro - UFRRJ, Seropédica, RJ, Brasil.

${ }^{8}$ Veterinary, Dsc. Instituto de Veterinária, Universidade Federal Fluminense - UFF, Niteroi, RJ, Brasil.

9 Veterinary, Dsc. Departamento de Medicina e Cirurgia Veterinária, Instituto de Veterinária, Universidade Federal Rural do Rio de Janeiro - UFRRJ, Seropédica, RJ, Brasil.
\end{abstract}

\begin{abstract}
Brachycephalic breeds possess higher vasovagal tone than do nonbrachycephalic breeds. Upper airway obstruction impairs the inspiratory effort by reducing the normal parasympathetic inhibition that occurs during this phase of the respiratory cycle. Sixteen dogs with nasal stenosis were included in this study, and an analytical and progressive analysis of the evolution of Heart Rate Variability (HRV) was performed at various time points: before the surgical procedure (day 0 ), and after the procedure on days 30 and 60. Surgical correction was performed using the vestibuloplasty technique, and HRV analysis was recorded via prolonged electrocardiography. Further, an analysis of the time domain indices was performed. Regarding clinical findings, an improvement in the average heart and respiratory rates after rhinoplasty, as well as a reduction in parasympathetic tone and resultant bradyarrhythmias were noted in all patients. Regarding the time domain HRV indices, Root-Mean of square sucessive NN interval difference (rMSSD) and Standard Deviation of all normal NN interval (SDNN) associated with the average heart rate, compared at different time points, strongly suggested that the reduction in parasympathetic stimulation was related to the reduction in HRV in these animals. The findings related to a reduction in the frequency of bradyarrhythmias corroborate the interpretative analysis of Lorenz graph indices, where there is a reduction in the cardiovagal index, without a significant alteration in the cardiosympathetic indices throughout the study period. The rMSSD index is the early-altered time-domain HRV index that can be used as an indicator of increase in parasympathetic activity caused by brachycephalic syndrome. The present study aimed to evaluate HRV through prolonged electrocardiographic examination, observing the excess of parasympathetic stimulation and the resultant bradyarrhythmias. In addition, evaluation of the clinical consequences of increased parasympathetic tone and the possibility of an improvement in autonomic balance following surgery, resulting in an improved quality of life and overall life expectancy in these patients, was performed.
\end{abstract}

Keywords: airway disease, brachycephalic syndrome, autonomic balance, dogs.
BJ

p-ISSN 0100-2430

How to cite: Santos Filho, M., Hainfellner, D. C. Lemos, N. M. O., Macambira, K. D. B., Carmo, J. S., Alberigi, B. R. S., Athar, C. V. A., Mendes Junior, A. F., Veiga, C. C. P., Soares, A. M. B., Botteon P. T. L., Fernandes, J. I. \& Paiva, J. P. (2020).Study of heart rate variability in dogs with brachycephalic syndrome that underwent rhinoplasty. Brazilian Journal of Veterinary Medicine, 42: e104920. http:// dx.doi.org/10.29374/2527-2179.bjvm104920

Financial support: The present work was carried out with the support of the Coordination of Improvement of Higher Education Personnel - Brazil (CAPES - Coordenação de Aperfeiçoamento de Pessoal de Nível Superior) - Financing Code 001. The present work is financed by FAPERJ (development agency of the state Rio de Janeiro that encourage research) scholarship for one of the authors.

Conflict of interests: No conflict of interests declared concerning the publication of this article.

Received: April 17, 2019

Accepted: January 23, 2020

The study was carried out at at the Hospital Veterinário de Pequenos Animais, Universidade Federal Rural do Rio de Janeiro - UFRRJ, Seropédica, RJ, Brasil.

\section{*Correspondence}

Mário dos Santos Filho

Instituto de Veterinária, Universidade Federal Rural do Rio de Janeiro - UFRRJ

Rodovia BR 465, Km 7, Campus Universitário, Bairro Zona Rural

CEP 23897-000 - Seropédica (RJ), Brasil

E-mail: mariosantoscg@gmail.com

Copyright Santos Filho et al. This is an Open Access article distributed under the terms of the Creative Commons Attribution Non-Commercial License which permits unrestricted non-commercial use, distribution, and reproduction in any medium provided the original work is properly cited. 


\section{Resumo}

As raças braquicefálicas apresentam índice de tônus vasovagal maior que cães não braquicefálicos. O processo obstrutivo de vias aéreas superiores prejudica o trabalho inspiratório reduzindo a inibição parassimpática normal desta fase do ciclo respiratório. Foram incluídos 16 cães com estenose de narinas, onde realizou-se o estudo analítico e progressivo da evolução dos achados da VFC em diferentes momentos, antes do proedimento cirúrgico (dia 0) e após o procedimento em dois momentos, 30 e 60 dias. A correção cirúrgica procedeu-se por meio da técnica de alavestibulplastia e a análise da VFC foi registrada por meio da eletrocardiografia prolongada. Para este exame foi realizada análise dos índices no domínio no tempo. Quanto aos achados clínicos houve melhora na avaliação da freqüência cardíaca e respiratória média após a cirurgia de rionoplastia, bem como redução da atividade parassimpática sob o Sistema Nervoso Autônomo (SNA), no que diz respeito às bradiarritmias em todos os pacientes. Quanto aos índices de VFC no domínio do tempo, rMSSD (Root-Mean of square sucessive NN interval difference) e SDNN (Standard Deviation of all normal NN interval) associados aos achados da frequência cardíaca média, comparados nos momentos distintos, trouxeram fortes indícios que a redução da estimulação parassimpática está relacionada a redução da VFC nesses animais. Os achados relacionados a redução das bradiarritmias corroboram para a análise interpretativa dos índices do gráfico de Lorenz, onde ocorre redução do índice cardiovagal, sem alteração significativa dos índices cardiosimpáticos ao longo do estudo. O rMSSD é o índice de VFC no domínio do tempo que precocemente alterado pode ser utilizado como indicador do aumento da atividade parassimpática causada pela Síndrome Braquicefálica (SB). O presente estudo tem por objetivo avaliar a VFC, por meio de exame eletrocardiográfico prolongado, observando o excesso da estimulação parassimpática no que tange a ocorrência de bradiarritmias e suas consequências clinicas, e a possibilidade de melhora do balanceamento autonômico após o tratamento, aumentando a qualidade e expectativa de vida destes pacientes.

Palavras-chave: doença das vias aéreas, síndrome do braquicefálico, balanço autonômico, cães.

\section{Introduction}

Brachycephalic syndrome is characterized by a combination of primary anatomical soft tissue deformities involving the upper airways. This set of abnormalities leads to increased resistance to the passage of air through the upper airways due to the obstruction and a consequent increase in the amount of negative pressure required for inspiration, which translates clinically into respiratory distress.

Animals with the above mentioned malformations and chronic respiratory disease tend to develop increased vagal tone secondary to the airway obstruction, triggering bradyarrhythmias such as sinus bradycardia and sinus arrest. The assessment of heart rate variability (HRV), or the change in heart rate over time, indicating autonomic modulation of the heart, is related to the prognosis and determination of the risk of death in some conditions, as well as to the somatic control over the variable intrinsic and extrinsic factors to which organisms are exposed.

In brachycephalic dogs, once surgical correction of the obstructed airway has been performed, the reestablished airflow reduces respiratory work and the resulting hypoxia, which may be reflected by a significant improvement in HRV.

The aim of this study was to determine HRV via prolonged electrocardiography in dogs with brachycephalic syndrome undergoing rhinoplasty.

\section{Materials and methods}

\section{Study location}

The study was conducted at Small Animal Veterinary Hospital - Universidade Federal Rural do Rio de Janeiro, where the clinical and complementary examinations, as well as the rhinoplasty procedure, were performed. Biochemical and hematological analyses as well as antigen detection for Dirofilaria immitis and microfilaria screening were performed at Clinical Pathology Laboratory.

\section{Inclusion and exclusion criteria}

Animals that met the following inclusion criteria were selected: patients with brachycephalic syndrome with nasal stenosis diagnosed upon visual inspection, and without any excluding factors (structural heart disease, pathological arrhythmias, and heartworm disease, as well as endocrine and 
respiratory comorbidities); patients between six months and five years of age, regardless of their gender and reproductive status (Moraes, 2012). A representation of nasal stenosis is provided in Figure 1.

Our study excluded animals that possessed such comorbidities as: respiratory disease diagnosed on chest X-ray imaging; cardiac disease, with the exception of cor pulmonale, diagnosed on Doppler echocardiography; blood dyscrasias that prohibited the surgical procedure; alterations in the renal and hepatic serum biochemical profiles that prohibited anesthesia; or infection with Dirofilaria immitis. A request for removal from the study by the owner also led to exclusion of the animal.

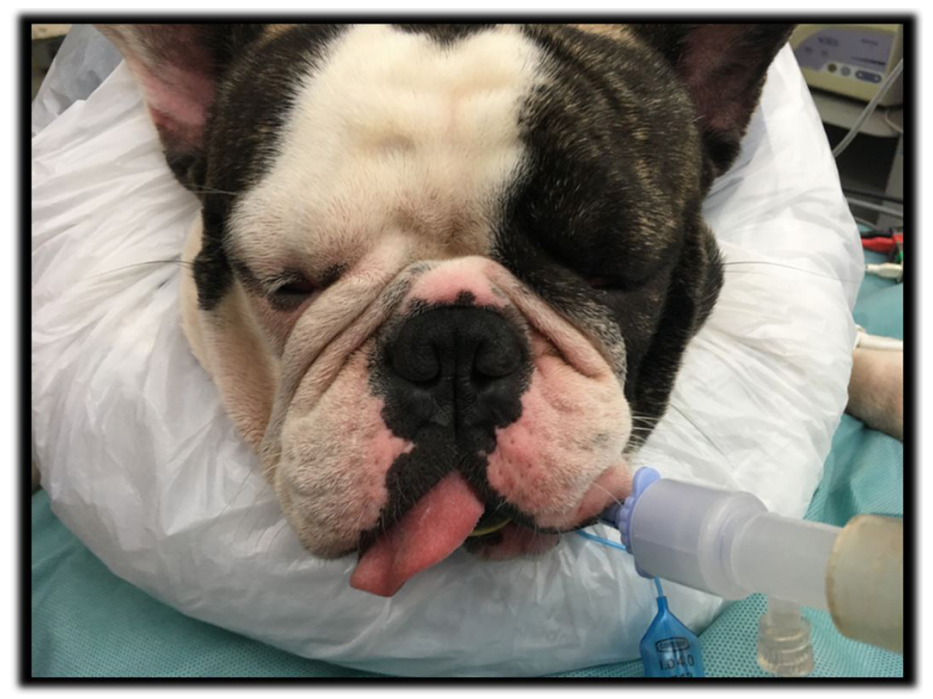

Figure 1. Anesthetized patient, positioned in prone position, showing nostril stenosis, moments before the rhinoplasty surgical procedure (Source: Personal Archive).

\section{Clinical evaluation}

Initially, the animal was acclimatized to the office and, for this purpose, remained for at least 20 minutes in an exam room, near the examiner. This allowed the animal to adapt to the location and to the presence of the examiner. During this period, anamnesis was performed and the owner was asked about the previous history of the animal.

After completing the questionnaire form, we proceeded to the measurement of systemic systolic blood pressure, using the noninvasive technique with the aid of a Doppler apparatus, sphygmomanometer, and veterinary cuff. Measurements were performed by the same operator each time, following consensus recommendations for systolic blood pressure measurements (Acierno et al., 2018). At the end of this stage, the animal was physically examined and the vital parameters were measured. Cardiac and pulmonary auscultation was performed.

\section{Laboratory tests}

To obtain the blood sample, puncture of the cephalic, saphenous, or jugular vein was performed, using proper aseptic technique. Five ml of blood was collected and the sample divided into two tubes, one with and one without anticoagulant, and both were stored under refrigeration. From the sample collected, a complete blood count was performed as well as serum biochemical analysis including renal and hepatic indicators. The blood sample was tested for the presence of antigens to Dirofilaria immitis via the Snap 4DX ${ }^{\circledR}$ Plus test and for the presence of microfilariae by the modified Knott method.

\section{Preoperative Electrocardiogram (ECG)}

The heart rate was assessed via electrocardiographic examination, during which the animal was positioned in the right lateral decubitus position, with the help of its owner. Alligator-type electrodes were properly positioned on the thoracic and pelvic limbs, according Tilley (1992). 
The exams were performed with the aid of a digital electrocardiography device, connected to a computer to allow visualization of the electrocardiographic tracing. The tracing was recorded for a period of 3 minutes; then, printing and analysis of the data were performed according to established reference values (Tilley, 1992).

\section{Doppler Echocardiography (ECO)}

The thoracic region of the animal was trichotomized bilaterally, and then, conductive gel was applied to the probe to allow performance of the examination. The animal was restrained by the examiner and a staff assistant. Patient positioning was in left lateral decubitus, without the use of sedative medications.

Examination involved the use of a Doppler echocardiographic device and two sector transducers. Each examination was performed by a single investigator, who did not have access to data acquired in the stages prior to the echocardiogram.

For the Doppler echocardiographic evaluation, previously recognized quadrants were evaluated in order to allow measurement of the size of the cardiac chambers, assessment of valve degeneration, and Doppler evaluation of the pressure gradient of the pulmonary and aortic flow (Boon, 2005). The ejection fraction and shortening fraction were measured following the Teicholz technique.

All patients that met the inclusion criteria underwent chest radiographic evaluation to identify signs of congestive heart failure and concomitant respiratory disease. Thoracic radiographs were obtained in three positions: right lateral, left lateral, and ventral-dorsal, in order to allow evaluation of the cardiorespiratory system. All images were obtained using conventional radiographic apparatus and a digitizer.

\section{Extended electrocardiography}

An electrocardiographic device from the manufacturer InPulse ${ }^{\circledR}$ was utilized, and the electrodes were attached to the patient, according Tilley (1992). The animal was restrained by a trained professional, with assistance provided by the patient's investigator. After the end of the 5-minute period, the equipment was removed and the data were saved for further analysis.

The parameters evaluated were the minimum heart rate, average heart rate, maximum heart rate (Figure 2), number of QRS complexes present during the 5-minute monitoring period, and the time domain HRV including Standard Deviation of all normal NN interval (SDNN), Standard Deviation of the Average NNinterval (SDANN), Root-Mean of square sucessive NNinterval difference (rMSSD), and nonlinear findings (Approximate Entropy - ApEn, cardiosympathetic index - CSI, cardiovagal índex - CVI, alfa 1 and alfa 2) (Figure 3) (De Giorgio et al., 2010).

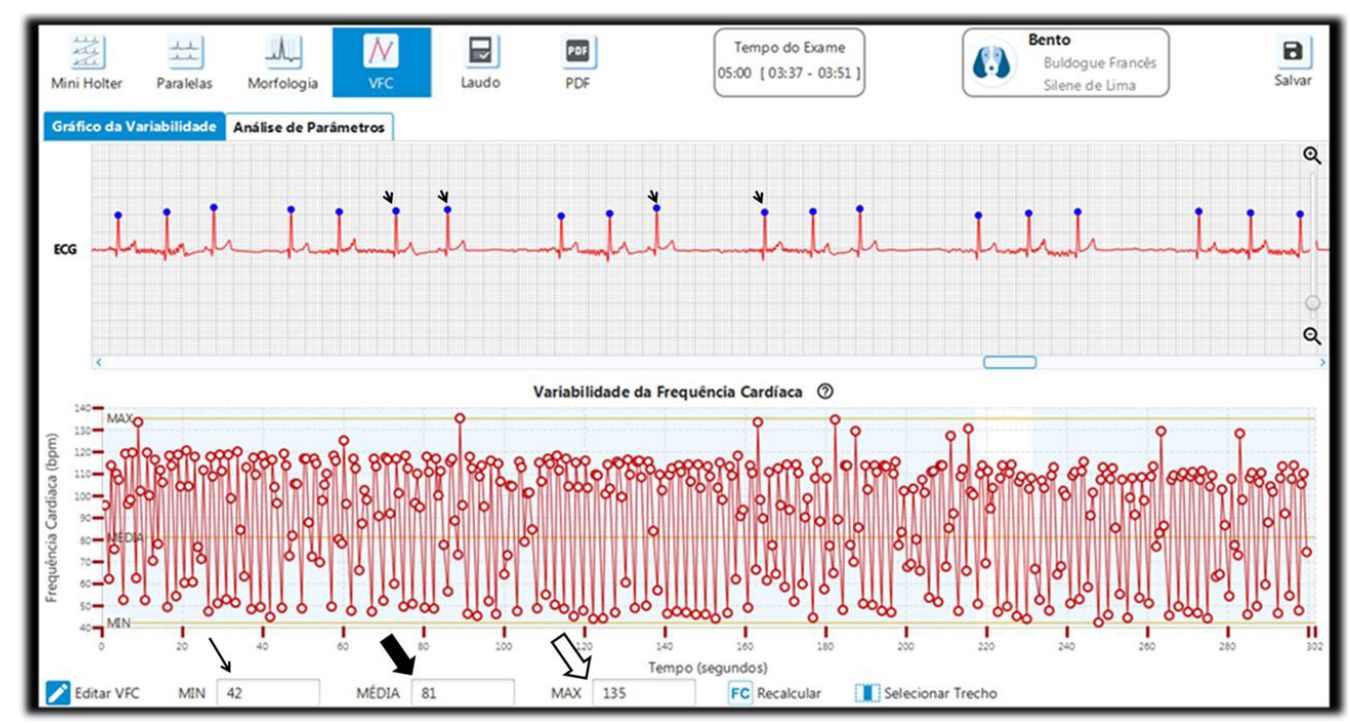

Figure 2. Heart rate variability, showing the R-R (arrowhead), minimum (arrowhead), average (filled arrow), and maximum (arrow) heart intervals (Source: Personal Archive). 


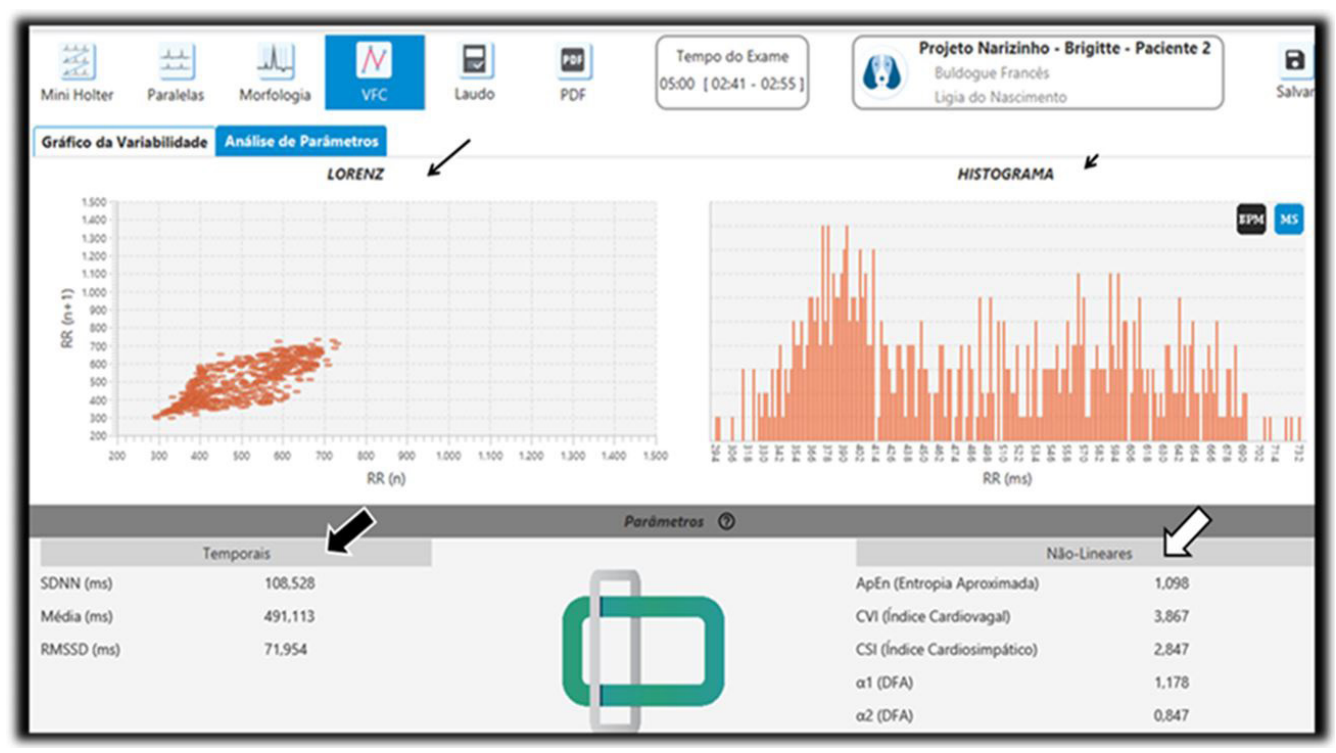

Figure 3. Heart rate variability, showing time indices (SDNN, SDANN-Mean, and rMSSD) (filled arrow), nonlinear methods (ApEn, CVI, CSI, Alpha 1 and Alpha 2) (arrow outline), and graphs of Lorenz (arrowhead) and Histogram (arrow) of all record (Source: Personal Archive).

\section{Experimental Design}

\section{Extended electrocardiography - Day 0}

Day O was established as the day the electrocardiographic recordings for HRV analysis were obtained. The patients were positioned in the right lateral decubitus position, and restrained by the investigators themselves after bilateral thoracic region trichotomy was performed.

The prolonged electrocardiographic examination was performed using an InCardio ${ }^{\circledR}$ recording device and was analyzed using proprietary software. The patient was positioned in right lateral recumbency and was restrained by the investigator and a trained professional. The same investigator was used each time. Following trichotomy and sterilization with 70\% ethyl alcohol, alligator clips were applied to the thoracic and pelvic limbs of the animals and were coupled with the lead electrodes. After fixation of the electrodes in the predetermined locations, the recording was begun, during which time the animal remained with its guardian. The examination was performed over a five-minute period. and any cardiac events that occurred were recorded.

After the recording period ended, the electrodes were removed and the data were compiled for further analysis. The same animals then underwent the same process, 30 days and 60 days after the surgical procedure was performed to correct nasal stenosis.

\section{Surgical procedure}

The surgical procedures were performed on day 0, following the previously described clinical evaluation and surgical screening. Shortly after the prolonged electrocardiography was performed, the patients were directed to an air-conditioned room free of stressful stimuli, where they were prepared for the anesthetic procedure.

Intravenous catheters were placed and fluid therapy was begun. Intravenous morphine $(1 \mathrm{mg} / \mathrm{kg})$ was administered as a Pre-Anesthetic Medication (PAM). As the PAM began to take effect, the patient was directed to the operating room, where the surgical preparation continued. Intravenous propofol (3mg/kg/IV) was then used to induce anesthesia. Anesthetic maintenance was achieved with isoflurano (1,5\%) in oxygen. Following trichotomy and aseptic preparation of the surgical region, the patient was positioned in sternal decubitus with the head slightly raised. The facial area was covered by a sterile field cloth, allowing visualization of only the region of the nostrils.

The surgical procedure consisted of excision of the wing portion of the hypertrophied nostril responsible for the stenosis (Fossum \& Duprey 2005), thus freeing the opening of the nasal cavity. 
The vestibuloplasty technique was used, employing an iodine laser device with an infrared wavelength.

After the procedure was complete, the isoflurane supply was stopped and the animal was allowed to awaken. Meloxicam $(0,2 \mathrm{mg} / \mathrm{kg}$ ) was administered intravenously for postoperative pain control. The patient was discharged from the hospital occurred after a complete anesthetic recovery, with stability of the vital signs including, body temperature, heart rate, respiratory rate, and systolic blood pressure.

Dipyrone $(25 \mathrm{mg} / \mathrm{kg})$ was prescribed for oral administration every 8 hours, for 3 days. Oral cephalexin $(20 \mathrm{mg} / \mathrm{kg}$ ) was prescribed for administration every 12 hours for 10 days, as well as $1 \mathrm{ml}$ beclomethasone dipropionate diluted in $3 \mathrm{ml}$ saline $(0,9 \%)$ to be used for nebulization twice daily for 7 days. An anti-infectious ointment containing urea, gentamicin, sulfadiazine, sulfanilamide, and vitamin A, used to stimulate epithelial healing, was dispensed for application to the nostrils, after cleaning with saline and gauze, twice daily for seven days.

Surgical evaluation was performed 7 days postoperatively, when all physical examinations were repeated.

\section{Extended electrocardiography - Day 30 and 60}

On days 30 and 60 after the first evaluation, prolonged electrocardiography was performed to allow comparison of HRV in animals at different time points (days 0, 30, and 60). This was performed on the same patients with the same investigator, under the same conditions, and using the same methodology.

\section{Statistical analyses}

From the collected information a database was created using the Microsoft Excel ${ }^{\odot} 2013$ program, $^{2}$ and all relevant descriptive statistical data as well as a comparison of the variables were analyzed using the BioEstat version5. $3^{\circledR}$ program (Instituto de Desenvolvimento Sustentável Mamirauá).

Data normality was verified using the Shapiro-Wilk test. The Dixon test was used for the recognition and exclusion of values discrepant from the normal distribution. The statistical procedure used for comparison between groups with quantitative variables was the one-way ANOVA with the Tukey post hoc test. The significance index adopted for the analyses was $\mathrm{p} \leq 0.05$. All data were presented as mean \pm SD (Sampaio, 2002).

\section{Results and discussion}

The experimental design of the present study allowed the comparison of HRV indices between animals with upper airway obstructions before and after rhinoplasty, comparing moments in these patients over time (Kleiger et al., 2005), under the hypothesis of reversing a possible autonomic imbalance on the heart.

To this end, it was necessary to adopt as an inclusion criterion upper airway obstruction, particularly nasal stenosis, which is easy to measure being based on the physical evaluation of the patient. This has been widely used in the clinical diagnosis of upper airway obstruction Bofan et al. (2015).

Since nasal stenosis was the first criterion used for selecting the animals that would constitute the experimental group, other demographic data such as breed, sex, and reproductive status were not set as selection criteria.

As a criterion for inclusion of the animal in the study, nasal stenosis was required to be present as the key manifestation of brachycephalic syndrome. The objective of selecting this criterion was to screen animals that presented with rostral obstructions, that could, after surgical correction and the reestablishment of airflow through the nasal passages, reflect an improvement in the autonomic influences on the physiological mechanisms that contribute to HRV.

In the physical examination, a significant difference was observed in the heart rate between day 0 and days 30 and 60 following rhinoplasty. This finding is expected due to a decrease in vagal stimulation that reduces the inhibitory effects on the sinus node (Bosquet et al., 2007).

There was also a trend towards Heart Rate (HR) stabilization when comparing values from days 30 and 60. It is believed that this finding is related to the fact that there is a reduction in 
parasympathetic activity by the vagus nerve after surgery, reducing the degree of respiratory influence on the sinus node in dogs. There will not necessarily be an increase in sympathetic activation as a result of this mechanism (Goldvberger, 1999) (Table 1).

Table 1. Heart rate distribution, in beats per minute, recorded during the physical assessment of brachycephalic dogs, from January 2018 to December 2018, in the city of Seropédica, before (day 0) and after the rhinoplasty procedure (days +30 and +60 ).

\begin{tabular}{cccc}
\hline \multirow{2}{*}{ Heart Rate } & \multicolumn{3}{c}{ Day } \\
\cline { 2 - 4 } & 0 & +30 & +60 \\
\hline Average $(\mathrm{bpm}) \pm \mathrm{SD}$ & $120 \pm 12.11^{\mathrm{a}}$ & $142 \pm 11.83^{\mathrm{b}}$ & $138 \pm 7.18^{\mathrm{b}}$ \\
\hline
\end{tabular}

Different letters along the lines ("a" and "b") correspond to the statistical difference at the 5\% level. bpm: beats per minute; SD: Standard Deviation.

When analyzing the respiratory rate in dogs with Brachycephalic Syndrome (BS) before and after surgical correction, it was noted that preoperatively, the patients displayed higher values. This result is consistent with that expected in an animal with an upper airway obstruction, where the increased respiratory rate results from an attempt to improve oxygenation. Inspiratory dyspnea results in a breathing cycle that is shorter and faster than normal (Park et al. 2008) (Table 2).

Table 2. Distribution of respiratory rate, in movements per minute, recorded during the physical evaluation of brachycephalic dogs, from January 2018 to December 2018, in the city of Seropédica, before (day 0) and after rhinoplasty procedure (days +30 and +60 ).

\begin{tabular}{|c|c|c|c|}
\hline \multirow{2}{*}{ Respiratory Rate } & \multicolumn{3}{|c|}{ Day } \\
\hline & 0 & +30 & +60 \\
\hline Average $(\mathrm{rmpm}) \pm \mathrm{SD}$ & $39,25 \pm 4,52^{\mathrm{a}}$ & $35,37 \pm 3,48^{b}$ & $34,31 \pm 4,58^{\mathrm{b}}$ \\
\hline \multicolumn{4}{|c|}{$\begin{array}{l}\text { Different letters along the lines ("a" and "b") correspond to the statistical difference at the } 5 \% \text { level. rmpm: respiratory movements per } \\
\text { minute; SD: Standard Deviation. }\end{array}$} \\
\hline \multirow{2}{*}{\multicolumn{4}{|c|}{$\begin{array}{l}\text { It is a fact that the respiratory rate and breathing pattern can be used to identify obstructive } \\
\text { airway diseases (Paiva, 2005). From the data collected in this study, we can infer that the respiratory } \\
\text { rate was sensitive to several anatomical variables, among which is the upper airway obstruction } \\
\text { that directly influences the type and rate of respiration (Rozanski, 2015). } \\
\text { The results of the study of Heart Rate Variability in the comparison of the time domain indexes } \\
\text { of this tool (SDNN, SDANN, rMSSD) and the minimum, average and maximum heart rates (HR), } \\
\text { being the average of the group "n", before and after rhinoplasty treatment are presented below } \\
\text { (Table 3). }\end{array}$}} \\
\hline & & & \\
\hline \multicolumn{4}{|c|}{$\begin{array}{l}\text { Table 3. Mean and Standard Deviation of Time Domain Heart Rate Variability and Minimum, Average and } \\
\text { Maximum Heart Rate measurements of animals before (day } 0 \text { ) and after rhinoplasty procedure (days }+30 \text { and }+60 \text { ). }\end{array}$} \\
\hline \multirow{2}{*}{ Variables HRV } & \multicolumn{3}{|c|}{ Day } \\
\hline & 0 & +30 & +60 \\
\hline $\operatorname{SDNN}(\mathrm{ms})$ & $146,95 \pm 83,46^{a}$ & $105,88 \pm 55,81^{b}$ & $93,68 \pm 49,24^{b}$ \\
\hline SDANN (ms) & $529,12 \pm 120,36^{a}$ & $481,53 \pm 84,63^{b}$ & $480,21 \pm 76,67^{b}$ \\
\hline $\operatorname{rMSSD}(\mathrm{ms})$ & $186,54 \pm 137,85^{a}$ & $120,59 \pm 73,68^{b}$ & $117,85 \pm 80,89^{b}$ \\
\hline Minimum HR (bpm) & $67,25 \pm 27,14^{*}$ & $64,43 \pm 19,51^{*}$ & $62,31 \pm 17,07^{*}$ \\
\hline Average HR (bpm) & $119,18 \pm 30,06^{a}$ & $127,68 \pm 23,60^{b}$ & $127,56 \pm 21,79^{*}$ \\
\hline Maximum HR (bpm) & $183,93 \pm 29,14^{*}$ & $192,75 \pm 42,02^{*}$ & $187,43 \pm 33,54^{*}$ \\
\hline
\end{tabular}

HRV: Heart Rate Variability; SDNN: standard deviation of all normal RR intervals of the exam; SDANN: standard deviation of means of normal RR intervals measured every five minutes; rMSSD: square root mean of the sum of the squared difference of normal RR intervals adjacent to the whole examination; HR: Heart Rate; SD: Standard Deviation; ms: milliseconds; bpm: beat per minute. Different letters ("a" and "b") along the same line indicate statistical difference at $5 \%$ level. Asterisks $\left({ }^{*}\right)$ along the same line indicate no statistical difference at the $5 \%$ level. 
Only a short time after surgical correction of the nasal stenosis, the three HRV indices showed a reduction in values when compared to the time before treatment. However, this reduction was only verified in the SDNN index, when its value on day 0 was compared to the values obtained on days $30(t=2,75 ; \mathrm{p}=0,0145)$ e $60(\mathrm{t}=2,42 ; \mathrm{p}=0,0281)$. Comparing the records from days 30 and 60, there was no statistically significant difference $(t=0,977 ; \mathrm{p}=0,34)$ (Figure 4 ).

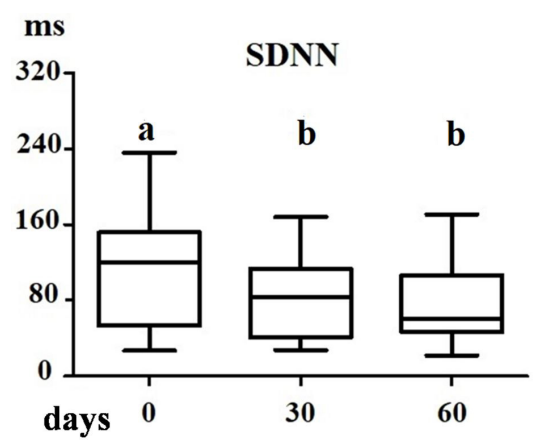

Figure 4. Comparison between mean values in milliseconds (ms), as a function of days, in relation to the SDNN value, before and after the rhinoplasty surgical procedure. Different letters ("a" and "b") along a column with significant difference at $5 \%$ level.

Regarding the SDANN values, a statistically significant difference was observed when comparing the records from day 0 with those from days 30 and $60 \mathrm{t}=2,47 ; \mathrm{p}=0,0255 \mathrm{e} \mathrm{t}=1,89 ; \mathrm{p}=0,0390$ ). When comparing days 30 and 60 , there was no significant difference $(t=0,084 ; p=0,93)$ (Figure 5 ).

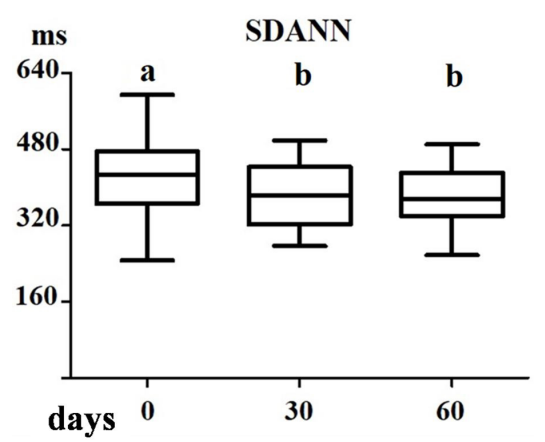

Figure 5. Comparison between the mean values in milliseconds (ms), as a function of days, regarding the SDANN value before and after rhinoplasty surgery. Different letters ("a" and "b") along the one of the columns indicate significant difference at $5 \%$ level.

Regarding the rMSSD index, its value on day 0 was significantly less than that of days 30 and 60 $(\mathrm{t}=2,81 ; \mathrm{p}=0,0130$ e $\mathrm{t}=2,041 ; \mathrm{p}=0,0296$, respectively). Comparing days 30 and 60, however, there was no significant difference in value (t=0,157; $\mathrm{p}=0,877$ ) (Figure 6).

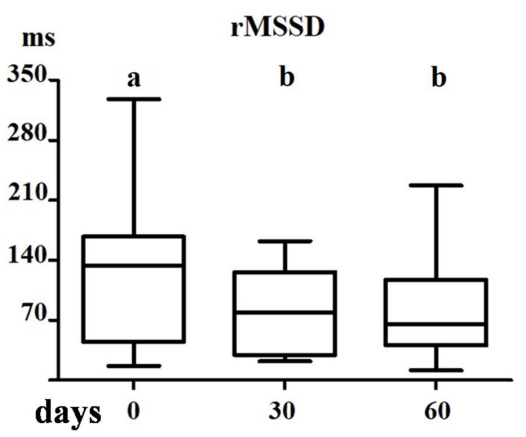

Figure 6. Comparison between mean values in milliseconds (ms), as a function of days, regarding rMSSD value, before and after rhinoplasty surgery. Different letters ("a" and "b") along the one of the columns indicate significant difference at $5 \%$ level. 
The fact that there was no statistically significant difference in these indices between days 30 and 60 post-operatively suggests that the short evaluation period was not sufficient to allow normalization of the autonomic activity on the heart, although a significant reduction in these indices was noted immediately post-operatively (Logier et al., 2004). Further study is required to determine whether stabilization already occurring 30 days post-operatively, and not only that occurring long after the surgery, is of major relevance (Song et al., 2006).

The reduction in SDNN, because this is an index calculated from long-term records, does not specify whether what has occurred is a result of a reduction in parasympathetic activity or an increase in sympathetic activity. However, its association with reduced rMSSD, which is an index that estimates parasympathetic activity by analyzing RR intervals, may indicate that, in fact, surgical treatment of nasal stenosis and the accompanying upper airway obstruction may reduce parasympathetic activity in dogs (Paschoal et al., 2002).

Studies in humans with chronic respiratory disease indicate that parasympathetic stimulation from controlled deep breathing does not elicit the HRV response expected with increased vagal tone, as it does in healthy subjects (Doxey \& Boswood, 2004). On the other hand, the results of the present study, suggest that the imbalance in autonomic activity associated with brachycephalic syndrome in dogs is probably different than what is seen in humans with upper airway obstructions. A greater understanding of the relationship between HRV and autonomic activity is necessary in all animals, especially dogs, considering the existence of physiologic vagotonia, which causes the majority of dogs with BS to develop sinus arrhythmias (Rajendra Acharya et al., 2006). It is important to emphasize that with the decrease in respiratory effort and subsequent regulation of the respiratory cycle, there was a decrease in HRV.

Regarding HR, the maximum HR, mean HR, and minimum HR showed very slight variations at the different time points. However, the mean HR on day 0 as compared to day 30 was significantly different ( $t=-1,83 ; \mathrm{p}=0,0435)$ (Figure 7).

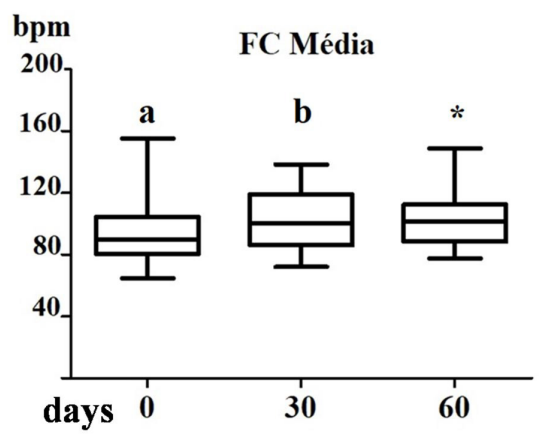

Figure 7. Comparison between the mean values in beats per minute (bpm), as a function of days, regarding the Average Heart Rate (HR) value, before and after rhinoplasty surgery. Different letters ("a" and "b") along the one of the columns indicate significant difference at $5 \%$ level. Asterisks $\left(^{*}\right)$ along the same line indicate no statistical difference at the $5 \%$ level.

Comparison of the mean HR between days 0 and 60 and between days 30 and 60, revealed no significant differences ( $p>0.05$ ). The minimum HR before and after surgery did not vary by a significant amount. These HRV statistics reinforce the thought that animals are more influenced by parasympathetic activity (Penttilä et al., 2001). The maximum heart rate increased after surgery, however this value did not reach statistical significance. This may be related to the need for a longer follow-up period to appreciate its normalization (Pumprla et al., 2002).

Regarding nonlinear methods, the accumulated data are presented in the table below (Table 4).

Approximate entropy (ApEn) revealed a significant difference between days 0 and 60 ( $\mathrm{t}=-2,15$; $\mathrm{p}=0,048$ ) (Figure 8 ).

This parameter quantifies the regularity, predictability, or complexity of experimental data. The higher the value of ApEn, the greater the complexity or irregularity of the signal; this indicates that we found a significant difference between the extreme days of the study. By analyzing the trends of the means at days 0,30, and 60, we were able to identify their association with the clinical improvement of the patient. In studies evaluating healthy individuals, a higher HRV is expected 
Table 4. Average and Standard Deviation of Heart Rate Variability measurements, nonlinear animal methods before (day 0) and after rhinoplasty procedure (days +30 and +60 ).

\begin{tabular}{lccc}
\hline \multicolumn{1}{c}{ Variables HRV } & \multicolumn{3}{c}{ Day } \\
\hline \multicolumn{1}{c}{ Nonlinear methods } & 0 & +30 & +60 \\
\hline Approximate entropy (ApEn) & $1,087 \pm 0,241^{\mathrm{a}}$ & $1,126 \pm 0,205^{*}$ & $1,207 \pm 0,272^{\mathrm{b}}$ \\
Cardiovagal index (CVI) & $4,057 \pm 0,610^{\mathrm{a}}$ & $3,855 \pm 0,533^{\mathrm{b}}$ & $3,780 \pm 0,514^{\mathrm{b}}$ \\
Cardiosympathetic index (CSI) & $1,608 \pm 0,795^{*}$ & $1,588 \pm 0,617^{*}$ & $1,558 \pm 0,809^{*}$ \\
Alfa 1 (DFA) & $0,657 \pm 0,405^{*}$ & $0,699 \pm 0,277^{*}$ & $0,662 \pm 0,293^{*}$ \\
Alfa 2 (DFA) & $0,635 \pm 0,318^{\mathrm{a}}$ & $0,671 \pm 0,288^{*}$ & $0,757 \pm 0,199^{\mathrm{b}}$ \\
\hline
\end{tabular}

HRV: Heart Rate Variability; SD: Standard Deviation; DFA: Analysis of Debugged Trend Fluctuations. Different letters ("a" and "b") along the same line indicate statistical difference at $5 \%$ level. Asterisks $\left({ }^{*}\right)$ along the same line indicate no statistical difference at the $5 \%$ level.

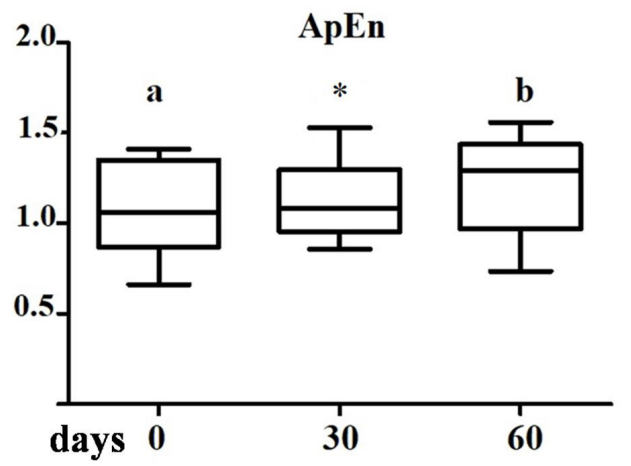

Figure 8. Comparison between the means of the indexes, as a function of days, regarding the Approximate Entropy (ApEn) value, before and after rhinoplasty surgery. Different letters ("a" and "b") along the one of the columns indicate significant difference at $5 \%$ level. Asterisks $\left({ }^{*}\right)$ along the same line indicate no statistical difference at the $5 \%$ level.

(Thuraisingham, 2006), because its capacity for adaptation will be greater, which will result in less regular recordings. This can also be explained as the entropy being high in a healthy individual compared to an individual with a morbid condition where the tendency of HRV is to be low with little variation in heart rate, therefore leading to low entropy (Radespiel-Tröger et al., 2003).

The cardiovagal index (CVI) showed a statistically significant difference when comparing the day 0 to days 30 and $60(t=2,340 ; p=0,033$ e $t=1,947 ; p=0,035)$. No significant difference between the days 30 and 60 was appreciated (Figure 9).

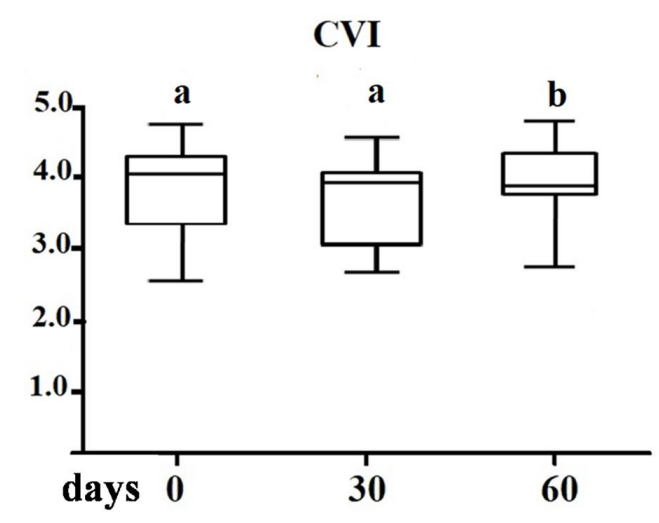

Figure 9. Comparison between the means of the indexes, as a function of days, referring to the value of Cardiovagal Index (CVI), before and after rhinoplasty surgery. Different letters ("a" and "b") along the one of the columns indicate significant difference at 5\% level. 
Considering the cardiosympathetic index (CSI), still referring to the nonlinear method, no statistical difference was evidenced in any comparison between the different time points (De Giorgio et al., 2010).

There are many controversial studies on the topic of chronic respiratory disease versus autonomic activity in the heart, which suggest the influence of a reduction in parasympathetic activity (Chua et al., 2008), a reduction in both sympathetic and parasympathetic activity (Aubert et al., 2003), and even a relative increase in sympathetic activity on heart regulation (Rasmussen et al., 2012).

The alpha 1 index showed no statistically significant difference between the different time points. However, the alpha 2 index showed a significant difference between days 0 and 60 $(\mathrm{t}=-2,087 ; \mathrm{p}=0,0270$ (Figure 10). This finding indicates the presence of HRV and represents its long-term correlation with the Detrended Fluctuation Analysis (DFA) signal, which leads to little change in the short-term findings (Santos et al., 2013).

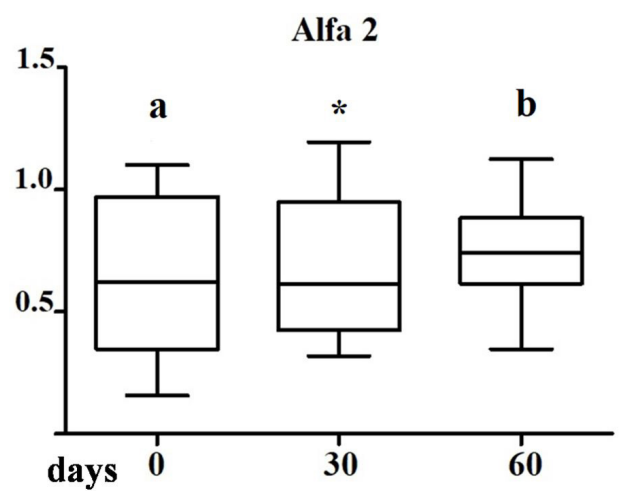

Figure 10. Comparison between the means of the indices, as a function of days, regarding the Alpha 2 (DFA) value, before and after rhinoplasty surgery. Equal letters ("a" and "b") along that of the columns indicate significant difference at the 5\% level. Asterisks ${ }^{*}$ ) along the same line indicate no statistical difference at the 5\% level.

As much as the actual pathophysiological mechanism by which the respiratory diseases in the dogs in this study increase parasympathetic activity (Shields Junior et al., 2009), efforts should be directed towards studies with larger numbers of participants, greater variability in the degree of obstructive disease, and more varied respiratory alterations.

Electrocardiographic examination revealed the presence of a sinus arrhythmia in 10 of the 16 dogs prior to treatment, and five of these animals had an associated sinus arrest or block. After treatment, it was observed that there was a tendency towards rhythm normalization on days 30 and 60. At the end of the study (day 60), sinus arrhythmia was observed in five of the animals, with only one maintaining a sinus block. The remaining animals in this group showed a normal sinus rhythm after treatment (Table 5).

Parallel to the HRV index results, the electrocardiographic record allowed the identification of the predominant heart rate over five minutes. The electrocardiographic recording obtained prior to treatment showed predominantly rhythms induced by high parasympathetic activity, such as sinus arrhythmia and sinus arrest or block (Figure 11) (Tilley \& Smith Junior, 2008), which occur mainly as a direct result of acetylcholine release near the muscarinic receptors of the sinus node (Malik et al.,1996). Following treatment, the prevalence of sinus arrest or block decreased to include only one animal, reinforcing the hypothesis that a reduction in parasympathetic activity occurs over time (Figures 12 and 13).

When considering the cardiac rhythms recorded prior to surgery, it was noticed that even the sinus arrhythmia, which is considered physiological in dogs due to its association with vagotonia (Tilley \& Smith Junior, 2008), occurred in ten animals The occurrence decreased by half following the surgical procedure.

Considering that even after acclimatization, the physical restraint required to perform the examination may be considered a stressor and may trigger a reduction in parasympathetic activity and/or an increase in sympathetic activity, it would be reasonable to expect the occurrence 
of rhythms induced by vagal tone. Considering that the same animals underwent the same procedures under the same conditions at subsequent evaluation dates, and that they showed a reduction in the frequency of rhythms induced by vagal tone, it seems apparent that upper airway obstruction increases parasympathetic activity.

Table 5. Electrocardiographic findings of the patients' heart rate before (day 0) and after the rhinoplasty procedure (days +30 and +60$)$.

\begin{tabular}{cccc}
\hline \multirow{2}{*}{ Animal } & & Rhythm & \\
\cline { 2 - 4 } & Day 0 & Day +30 & Day +60 \\
\hline 01 & RSA & RSA & RSA \\
02 & RSA & RSA & SR \\
03 & SR & SR & SR \\
04 & RSA / SA & RSA / SA & RSA / SA \\
05 & SR & SR & SR \\
06 & SR & SR & SR \\
07 & RSA / SA & RSA & SR \\
08 & RSA & RSA & RSA \\
09 & SR & SR & SR \\
10 & RSA / SA & RSA / SA & RSA \\
11 & RSA & RSA & SR \\
12 & SR & SR & SR \\
13 & SR & SR & SR \\
14 & RSA / SA & RSA & RSA \\
15 & RSA / SA & RSA & SR \\
16 & RSA & RSA & SR \\
\hline
\end{tabular}

RSA: Respiratory Sinus Arrhythmia; SA: Sinus arrest; SR: Sinus rhythm.

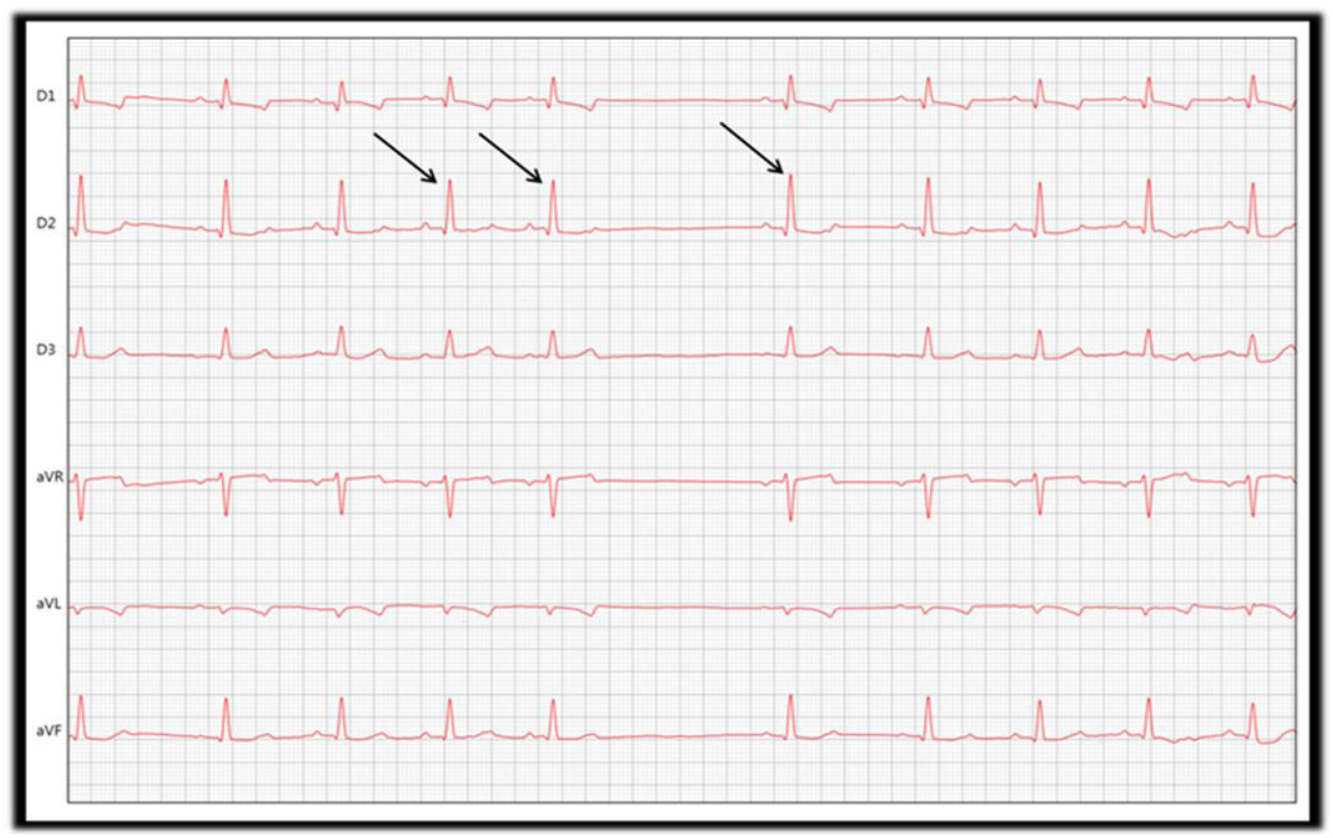

Figure 11. Electrocardiographic tracing at a speed of 50mm / s, showing tracing in bipolar leads, showing sinus arrest, represented by irregular R-R intervals (arrows), where the adjacent R-R interval is twice the length of the anterior interval. (Source: Personal Archive). 


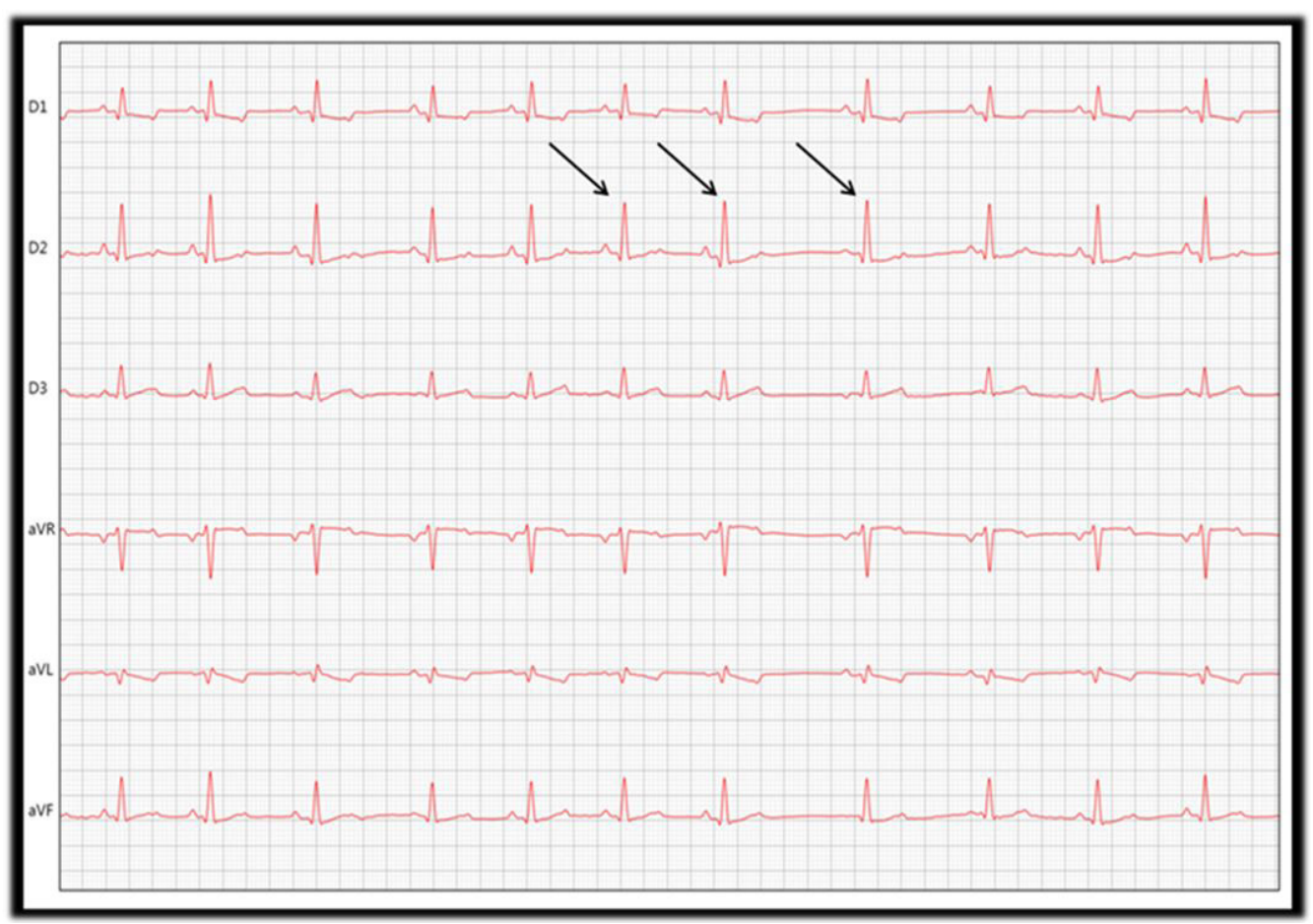

Figure 12. Electrocardiographic tracing at a speed of 50mm/s, showing tracing on bipolar leads, showing sinus arrhythmia, represented by irregular R-R intervals (arrows), not exceeding 50\% of the anterior interval. (Source: Personal Archive)

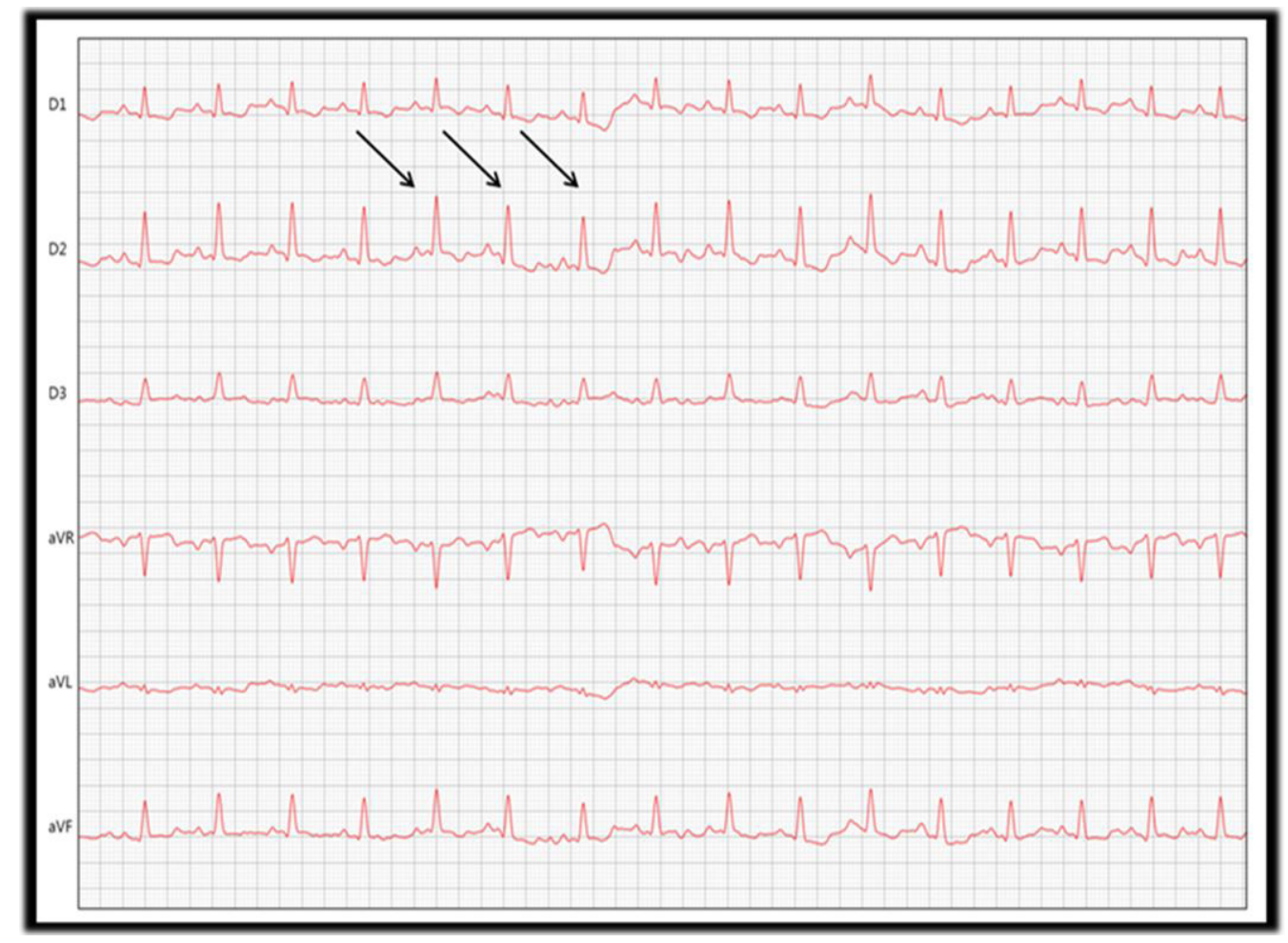

Figure 13. Electrocardiographic tracing at a speed of $50 \mathrm{~mm} / \mathrm{s}$, showing tracing on bipolar leads, showing sinus rhythm, represented by regular R-R intervals (arrows). (Source: Personal Archive). 
The high variability of heart rate is believed by many scholars to be associated with the balance of autonomic regulation of the heart (Bosquet etal., 2007; Vanderlei et al., 2009). However, it should be emphasized that in a species such dogs, in which parasympathetic activity is predominant, this should be interpreted cautiously in the face of varied influences and organic stressors such as disease. It should be considered that from the moment a young dog with an upper airway obstruction presents with high HRV, before procedures are undertaken to reestablish airflow, the disease may be exaggerating the autonomic imbalance.

Briefly, the present study contributes to the understanding of changes in HRV due to the evolution of BS. Considerable attention is paid to the reference values for each index, but because the values are specific for each individual, it is clear that changes in the actual values (such as an increase in the minimum heart rate) are associated with parasympathetic stimulation. It can be inferred that since autonomic modulation is related to the adaptation to a stressor or disease, the changes in the indices of HRV following surgical are associated with a reduction in parasympathetic activity, with the tendency towards greater sympathetic activation of the ANS.

\section{Conclusions}

1) On prolonged electrocardiographic examination, after surgical correction of nasal stenosis, the findings are characterized by a reduction in the occurrence of bradyarrhythmias, with an increase in the average heart rate and a reduction in the occurrence of respiratory sinus arrhythmia, with a tendency to establish a sinus rhythm.

2) The follow-up on time-domain HRV, based on the findings of increased rMSSD (Root-Mean of square sucessive NN interval difference), minimum heart rate and SDANN (Standart Deviation of the Average NN interval), and the maintenance of maximum heart rate, suggests a reduction in the influence of parasympathetic activity on the cardiovascular system, with a decrease in the frequency of bradyarrhythmias.

3) Heart rate variability at days 30 and 60 post-operatively reduces the cardiovagal indices, reinforcing the finding of reduced parasympathetic activity.

4) Increased parasympathetic activity in brachycephalic dogs is demonstrated by SDANN or the early-altered time-domain heart rate variability index.

5) Approximate entropy and cardiovagal index reinforce the finding of parasympathetic stimulation in obstructive airway diseases, with a reduction in these values a short while after reestablishment of normal airflow.

6) Upper airway obstruction increases HRV by increasing parasympathetic activity in autonomic regulation of the heart.

7) Brachycephalic animals are exposed to rhythm disturbances linked to increased parasympathetic activation over cardiac bathymotropism.

\section{Acknowledgements}

We thank the Clinical Pathology Laboratory and Small Animal Vetrinary Hospital - UFRRJ (Universidade Federal Rural do Rio de Janeiro), for the support.

\section{References}

Acierno, M. J., Brown, S., Coleman, A. E., Jepson, R. E., Papich, M., Stepien, R. L., \& Syme, H. M. (2018). ACVIM consensus statement: Guidelines for the identification, evaluation, and management of systemic hypertension in dogs and cats. Journal of Veterinary Internal Medicine, 32(6), 1803-1822. http://dx.doi.org/10.1111/jvim.15331. PMid:30353952.

Aubert, A. E., Seps, B., \& Beckers, F. (2003). Heart rate variability in athletes. Sports Medicine, 33(12), 889-919. http://dx.doi.org/10.2165/00007256-200333120-00003. PMid:12974657.

Bofan, A. B., Ionascu, I., \& Șonea, A. (2015). Brachycephalic airway syndrome in dogs. Scientific Works. Series $C$, Veterinary Medicine, 61(1), 103-112.

Boon, J. A. (2005). Ecocardiografia em Modo-M: uma avaliação quantitativa. In J. A. Boon (Ed.), Ecocardiografia Bidimensional e em Modo-M para o clínico de pequenos animais. (1st ed., pp. 39-52). Wyoming: Roca. 
Bosquet, L., Gamelin, F. X., \& Berthoin, S. (2007). Is aerobic endurance a determinant of cardiac autonomic regulation? European Journal of Applied Physiology, 100(3), 363-369. http://dx.doi.org/10.1007/s00421-0070438-3. PMid:17440748.

Chua, K. C., Chandran, V., Acharya, U. R., \& Lim, C. M. (2008). Cardiac state diagnosis using higher order spectra of heart rate variability. Journal of Medical Engineering \& Technology, 32(2), 145-155. http://dx.doi. org/10.1080/03091900601050862. PMid:18297505.

De Giorgio, C. M., Miller, P., Meymandi, S., Chin, A., Epps, J., Gordon, S., Gornbein, J., \& Harper, R. M. (2010). RMSSD, a measure of vagus-mediated heart rate variability, is associated with risk factors for SUDEP: the SUDEP-7 Inventory. Epilepsy \& Behavior, 19(1), 78-81. http://dx.doi.org/10.1016/j.yebeh.2010.06.011. PMid:20667792.

Doxey, S., \& Boswood, A. (2004). Differences between breeds of dog in a measure of heart rate variability. The Veterinary Record: Oxford, 154(1), 713-717. http://dx.doi.org/10.1136/vr.154.23.713. PMid:15214514.

Fossum, T. W., \& Duprey, L. P. (2005). Cirurgias do trato respiratório superior. In T. W. Fossum (Ed.), Cirurgia de pequenos animais (3th ed., p. 923-929). São Paulo: Rocca.

Goldberger, J. J. (1999). Sympathovagal balance: How should we measure it? American Journal of Physiology. Heart and Circulatory Physiology, 276(1), 1273-1280. http://dx.doi.org/10.1152/ajpheart.1999.276.4.H1273. PMid:10199852.

Kleiger, R. E., Stein, P. K., \& Bigger Junior, J. T. (2005). Heart rate variability: Measurement and clinical utility. Annals of Noninvasive Electrocardiology: Armonk, 10(1), 88-101. http://dx.doi.org/10.1111/j.1542-474X.2005.10101.x. PMid:15649244.

Logier, R., De Jonckheere, J., \& Dassonneville, A. (2004). An efficient algorithm for R-R intervals series filtering. Conference Proceedings:... Annual International Conference of the IEEE Engineering in Medicine and Biology Society, 6(1), 3937-3940. http://dx.doi.org/10.1109/IEMBS.2004.1404100. PMid:17271158.

Malik, M., Bigger, J. T., Camm, A. J., Kleiger, R. E., Malliani, A., Moss, A. J., \& Schwartz, P. J. (1996). Heart rate variability: standards of measurement, physiological interpretation, and clinical use. European Heart Journal, London, 17(3), 354-381. http://dx.doi.org/10.1093/oxfordjournals.eurheartj.a014868. PMid:8737210.

Moraes, P. (2012). Síndrome Aérea dos Braquicefálicos - Estenose de Narina em Cão: Relato de Caso. Revista Científica Eletrônica de Medicina Veterinária, 18(1), 1-8.

Paiva, J. P. (2005). Paralisis de Laringe. In: C. J. Mucha, C. Sorribas, \& F. C. Pellegrino (Eds.), Consulta Rapida em La Clinica Diaria (1st ed., pp. 17-20). Buenos Aires: Inter-Médica.

Park, D. H., Shin, C. J., Hong, S. C., Yu, J., Ryu, S. H., Kim, E. J., Shin, H. B., \& Shin, B. H. (2008). Correlation between the severity of obstructive sleep apnea and heart rate variability indices. Journal of Korean Medical Science, 23(2), 226-231. http://dx.doi.org/10.3346/jkms.2008.23.2.226. PMid:18437004.

Paschoal, A., Petreluzzi, S., \& Gonçalves, O. (2002). Estudo da variabilidade da frequência cardíaca em pacientes com doenças pulmonar obstrutiva crónica. Revista Ciencia Médica, 11(1), 27-37.

Penttilä, J., Helminen, A., Jartti, T., Kuusela, T., Huikuri, H. V., Tulppo, M. P., Coffeng, R., \& Scheinin, H. (2001). Time domain, geometrical and frequency domain analysis of cardiac vagal outfow: effects of various respiratory patterns. ClinicalPhysiology, 21(3), 365-376. PMid:11380537.

Pumprla, J., Howorka, K., Groves, D., Chester, M., \& Nolan, J. (2002). Functional assessment of heart rate variability: physiological basis and practical applications. International Journal of Cardiology, 84(1), 1-14. http://dx.doi. org/10.1016/S0167-5273(02)00057-8. PMid:12104056.

Radespiel-Tröger M., Rauh R., Mahlke C., Gottschalk T. \& Muck-Weymann, M. Agreement of two different methods for measurement of heart rate variability. ClinicalAutonomicResearch, 13(2):99-102, 2003.

Rajendra Acharya, U., Paul Joseph, K., Kannathal, N., Lim, C. M., \& Suri, J. S. (2006). Heart rate variability: A review. Medical \& Biological Engineering \& Computing, 44(12), 1031-1051. http://dx.doi.org/10.1007/s11517-006-0119-0. PMid:17111118.

Rasmussen, C. E., Falk, T., Zois, N. E., Moesgaard, S. G., Häggström, J., Pedersen, H. D., Ablad, B., Nilsen, H. Y., \& Olsen, L. H. (2012). Heart rate, heart rate variability, and arrhythmias in dogs with myxomatous mitral valve disease. Journal of Veterinary Internal Medicine, 26(1), 76-84. http://dx.doi.org/10.1111/j.1939-1676.2011.00842.x. PMid:22151356.

Rozanski, E. A. (2015). Oxygenation and ventilation. Veterinary Clinical Small Animals, 46(1), 1-10. PMid:26051823.

Sampaio, I. (2002). Estatística aplicada a experimentação animal (2nd ed., 265 p.). Belo Horizonte: Fundação de Estudo e Pesquisa em Medicina Veterinária e Zootecnia.

Santos, M. D. B., Moraes, F. R., Marães, V. R. F. S., Sakabe, D. I., Takahashi, A. C. M., Oliveira, L., Gallo Junior, L., Silva, E., \& Catai, A. M. (2013). Estudo da arritmia sinusal respiratória e da variabilidade da frequência cardíaca de homens jovens e de meia-idade. Revista da Sociedade de Cardiologia do Estado de São Paulo, 13(3 Supl A), 15-24.

Shields Junior, R. W. (2009). Heart rate variability with deep breathing as a clinical test of cardiovagal function. Cleveland Clinic Journal of Medicine, 76(Suppl2), S37-S4O. http://dx.doi.org/10.3949/ccjm.76.s2.08. PMid:19376980.

Song, J., Ogawa, M., Tan, A. Y., Chen, P., \& Lin, S. (2006, August 30 - September 3). Heart rate variability and autonomic nerve activities in ambulatory dogs. In IEEE Engineering in Medicine and Biology Society, EMBS Annual International Conference (pp. 1780-1783). New York, NY: EMB Executive Office.

Thuraisingham, R. A. (2006). Preprocessing RR interval time series for heart rate variability analysis and estimates of standard deviation of RR intervals. Computer MethodsandProgramsBiomedicine, 83(1), 78-82. http://dx.doi. org/10.1016/j.cmpb.2006.05.002. PMid:16806571. 
Tilley, L. P. (1992). Essential of canine and feline electrocardiography (3rd ed., 470 p.). Philadelphia: Lea \& Febiger.

Tilley, L. P., \& Smith Junior, F. W. (2008). Eletrocardiography. In L. P. Tilley, F. W. Smith Junior, M. A. Oyama \& M. M. Sleeper (4th ed., 49 p). Manual of canine and feline cardiology. Missouri: Saunders Elsevier.

Vanderlei, L. C. M., Pastre, C. M., Hoshi, R. A., Carvalho, T. D., \& Godoy, M. F. (2009). Noções básicas de variabilidade da frequência cardíaca e sua aplicabilidade clínica. Revista Brasileira de Cirurgia Cardiovascular, 24(2), 205217. http://dx.doi.org/10.1590/S0102-76382009000200018. PMid:19768301. 